\title{
Analyses of expressed sequence tags in Neurospora reveal rapid evolution of genes associated with the early stages of sexual reproduction in fungi
}

\author{
Kristiina Nygren ${ }^{1,5}$, Andreas Wallberg ${ }^{2}$, Nicklas Samils', Jason E Stajich ${ }^{3}$, Jeffrey P Townsend ${ }^{4}$, Magnus Karlsson ${ }^{1}$ \\ and Hanna Johannesson ${ }^{5^{*}}$
}

\begin{abstract}
Background: The broadly accepted pattern of rapid evolution of reproductive genes is primarily based on studies of animal systems, although several examples of rapidly evolving genes involved in reproduction are found in diverse additional taxa. In fungi, genes involved in mate recognition have been found to evolve rapidly. However, the examples are too few to draw conclusions on a genome scale.

Results: In this study, we performed microarray hybridizations between RNA from sexual and vegetative tissues of two strains of the heterothallic (self-sterile) filamentous ascomycete Neurospora intermedia, to identify a set of sex-associated genes in this species. We aligned Expressed Sequence Tags (ESTs) from sexual and vegetative tissue of $N$. intermedia to orthologs from three closely related species: N. crassa, N. discreta and N. tetrasperma. The resulting four-species alignments provided a dataset for molecular evolutionary analyses. Our results confirm a general pattern of rapid evolution of fungal sex-associated genes, compared to control genes with constitutive expression or a high relative expression during vegetative growth. Among the rapidly evolving sex-associated genes, we identified candidates that could be of importance for mating or fruiting-body development. Analyses of five of these candidate genes from additional species of heterothallic Neurospora revealed that three of them evolve under positive selection.
\end{abstract}

Conclusions: Taken together, our study represents a novel finding of a genome-wide pattern of rapid evolution of sex-associated genes in the fungal kingdom, and provides a list of candidate genes important for reproductive isolation in Neurospora.

Keywords: Neurospora, Reproductive genes, dN/dS, Speciation, Microarray

\section{Background}

Genes involved in sexual reproduction are found to evolve rapidly in diverse taxonomic groups (e.g., [1-3]). The phenomenon is especially well studied in animals, where rapidly evolving genes are found to be expressed in virtually all stages of reproduction, from mating to fertilization [1]. Large-scale evolutionary analyses show that, in general, genes expressed in animal reproductive

\footnotetext{
* Correspondence: hanna.johannesson@ebc.uu.se

${ }^{5}$ Department of Evolutionary Biology, Evolutionary Biology Centre, Uppsala University, Norbyvägen 18 D, SE-752 36, Uppsala, Sweden

Full list of author information is available at the end of the article
}

organs show a higher divergence than genes expressed in other tissues [4-7]. Examples of rapid evolution are also seen in self/non-self recognition genes in plants $[8,9]$ and in certain reproductive genes of a wide range of eukaryotic taxa, including algae and fungi [3,10-12]. The rapid evolution of reproductive genes is generally assumed to be adaptive [1] and in line with this assumption, positive selection as the driving force has been confirmed for many fast-evolving reproductive genes (e.g., [5,8,13-16]). Multiple hypotheses have been proposed to explain the rapid evolution of reproductive genes in animals and plants, including sexual selection, sexual 
conflict, sperm competition, self/non-self recognition and selection for reinforced prezygotic mating barriers between species (e.g., $[1,3,17])$.

Despite the widespread observations of fast-evolving reproductive genes within the animal kingdom, the rate of evolution of genes involved in sexual reproduction of fungi has scarcely been examined. A few examples of fungal reproductive genes that evolve rapidly have been reported, including the mating-type genes, pheromone precursor and receptor genes in filamentous ascomycetes $[12,15,18,19]$; for certain genes, this rapid evolution has been shown to be driven by positive selection $[15,18,19]$. Previous genomic comparisons between yeast species have indicated a high turnover of genes involved in sexual reproduction $[20,21]$. However, there have been no large-scale evolutionary analyses of genes involved in sexual reproduction in other fungi. Thus, it has been impossible to draw conclusions about a general pattern of rapid evolution of reproductive genes in this kingdom.

In this study, we identified and sequenced genes with relatively high expression during early mating between sexually compatible strains of the heterothallic (self-sterile) filamentous ascomycete Neurospora intermedia. Genomic data is at present not available for $N$. intermedia, and choosing it for our study made it possible to use our new data together with available genomic data from closely related Neurospora species to confirm rapid evolution of sex-associated genes in this fungal genus. In heterothallic species of Neurospora, individuals of two different mating types (mat $A$ and mat $a$, respectively) must meet in order to enter the sexual cycle. Distinct female and male reproductive structures are formed during mating, and individuals of both mating types can play both female and male roles. In the initial step of the mating process, a specialized female hypha (trichogyne) grows towards the male propagule (conidia or hyphal fragment) of the opposite mating type. This attraction is mediated by mating-type dependent pheromone signaling [22-24]. After cell fusion (plasmogamy) the male nucleus is transported through the trichogyne into the developing immature fruiting body (protoperithecium). Here the male and female nuclei line up and in parallel go through several nuclear divisions, before nuclear fusion (karyogamy) takes place. Karyogamy is shortly followed by meiosis, ascospore and fruiting body development, and the active discharge of the mature ascospores. The initial contact between sexual partners is mainly mating-type dependent and compatible individuals of different species of Neurospora are able to mate [25]. However, interspecific matings between $N$. crassa and $N$. intermedia show reduced reproductive success as compared to matings between conspecific individuals, indicating post-mating reproductive isolation between these species. Furthermore, reproductive isolation between species is reinforced in sympatry $[25,26]$, suggesting selection against hybridization. The genetic machinery underlying the early mating procedure (i.e., between plasmogamy and karyogamy), when mate recognition genes are functioning, is as yet largely unknown in Neurospora.

We identified genes with relatively high expression during the early phase of sexual reproduction in heterothallic Neurospora, and confirmed that the general trend of rapid evolution of sex-associated genes was upheld in this genus. Furthermore, among the sex-associated genes, we identified rapidly evolving candidate genes that might be involved in reproductive incompatibilities between taxa, such as the observed reinforcement between $N$. crassa and N. intermedia [25,27]. Finally, we used molecular evolutionary analyses to assess whether positive selection was a driving force for the rapid evolution.

\section{Results}

Identification of sexual, vegetative and constitutive gene categories in neurospora

With the goal of distinguishing categories of genes with constitutive expression from those exhibiting high relative expression during sexual or vegetative development, we performed competitive microarray hybridizations between RNA from sexual and vegetative tissue samples of two strains of Neurospora intermedia, using the $N$. crassa microarray (a whole-genome-spotted oligonucleotide microarray containing 9,826 open reading frames [28]). Sexual tissue constituted young fruiting structures formed in crosses of the two strains, and vegetative tissue was composed of young mycelia of the separately grown strains.

In total, 6,126 genes, represented by probes on the $N$. crassa microarray, exhibited well-measured signal and could be analyzed. The data have been deposited both in the Filamentous fungal gene expression database (FFGED) [29] with experiment ID 56 and in the NCBI Gene Expression Omnibus and are accessible through GEO Series accession number GSE37034. Of these 6,126 genes, Bayesian analyses of gene expression levels, using UBAGEL 3.6 [30,31], identified 509 genes that showed a significantly higher expression in the sexual tissue than in the vegetative tissue $(P<0.05), 589$ genes that showed a relative increase in expression in the vegetative sample $(P<0.05)$, and 5,028 expressed genes that were not found to be differentially expressed in our samples. These three groups define our "sexual", "vegetative", and "constitutive" gene categories, respectively. In addition, we constructed a subcategory of the sexual category based on a stringent false discovery rate, so that this category only contained the genes with $Q<0.10$. This subcategory is referred to as "sexual $Q<0.1$ ", and contained 112 genes. 


\section{EST sequencing of Neurospora intermedia and the building of four-way gene alignments}

We sequenced ESTs from clones of cDNA libraries constructed from RNA of $N$. intermedia sexual and vegetative tissue (1,920 and 768 clones, respectively). Four-way gene alignments were constructed by adding the assembled EST-sequences of $N$. intermedia to 3-way alignments of the publicly available genome sequences for the two heterothallic Neurospora species $N$. crassa and $N$. discreta, and the pseudohomothallic (partially self-sterile) N. tetrasperma. Of the 1,392 genes of $N$. crassa mapped to by ESTs of $N$. intermedia, 998 yielded 4-way orthologs including $N$. crassa, N. discrete, $N$. tetrasperma and N. intermedia. Of those 998, eight 4-way alignments were excluded due to lack of regions where the sequences from all four taxa were overlapping. Thus, in total there were 990 4-way single gene alignments without gaps. The mean alignment length for individual genes was $762 \mathrm{bp}$, on average including $96 \%$ of the nucleotides of the new $N$. intermedia EST-sequence and $62 \%$ of the previously aligned sequences of the other three species.

A majority of the genes in the 4-way alignments fell into one of the three categories, defined based on the microarray experiment: of the 990 genes, 99 (10\%), 94 (9\%) and $628(63 \%)$ fell into the sexual, vegetative and constitutive gene categories, respectively. The remaining 17\% (169 genes) did not have an identified category (i.e., data from the microarray analysis is missing for these genes). The subcategory "sexual $Q<0.1$ " contained 26 (2.6\%) genes with a 4-way alignment.

\section{Identification of rapidly evolving genes by maximum likelihood analyses}

To analyze the molecular evolution of genes expressed constitutively or relatively highly during sexual or vegetative growth, we used the maximum likelihood program codeml included in the PAML package version 4.3 $[32,33]$. The program codeml calculated $\mathrm{dN} / \mathrm{dS}$, the ratio of non-synonymous substitutions per non-synonymous site $(\mathrm{dN})$ to synonymous substitutions per synonymous site (dS) over branches in the phylogeny and/or over codons in a gene. We used the 4-way alignment described above to estimate i) the overall $\mathrm{dN} / \mathrm{dS}, \mathrm{dN}$ and $\mathrm{dS}$ for the genes in different categories, by using global models of $\mathrm{dN} / \mathrm{dS}$ among sites and branches, and ii) branch-specific evolutionary rates by using a two-ratio model of $\mathrm{dN} / \mathrm{dS}$, in which the branch of interest was specified as foreground and all remaining branches as background. By this approach, we identified 204 genes as more rapidly evolving (exhibiting higher $\mathrm{dN} / \mathrm{dS}$ ) than the mean for the complete phylogenetic tree and/or in any of the branches. Each of the genes and branch(es) for which a $d N / d S$ higher than mean was found, is shown in Additional file 1: Table S1 and summarized in Table 1 . Of the 204 rapidly evolving genes, 164 were found to be rapidly evolving using the global model, i.e., the global rate estimated for all four Neurospora branches together was significantly higher than the mean (Table 1). These genes were categorized as the "rapidly evolving Neurospora genes". We identified 49 rapidly evolving genes in the branch delineating $N$. intermedia, 41 in the $N$. crassa branch, 135 in the $N$. discreta branch, and 21 in the N. tetrasperma branch (Table 1). The number of branch-specific rapidly evolving genes in the phylogeny is lower in the shorter branches (indicated by branch specific dS, Figure 1), which is expected since the power to estimate $\mathrm{dN} / \mathrm{dS}$ is lower for genes exhibiting very few nucleotide changes. Most of the genes found to be rapidly evolving in each of the separate branches were also found among the rapidly evolving Neurospora genes (Additional file 1: Table S1).

Distribution of rapidly evolving genes in gene categories Of the 164 rapidly evolving Neurospora genes, 19 were found in the sexual gene category (Table 1). A higher proportion of genes in the sexual gene category were rapidly evolving (26 of 99: $26 \%$ ) as compared to the constitutive gene category (112 of 627: 18\%) (Table 1, Fisher exact test, two-tailed, $\mathrm{p}=0.036)$. The pattern was similar in the comparison between the sexual and vegetative

Table 1 Proportions of individual genes in each category that are found to be rapidly evolving in any of the codeml analyses

\begin{tabular}{|c|c|c|c|c|c|c|c|}
\hline \multirow[t]{3}{*}{ Gene category } & \multirow[t]{3}{*}{ Number of genes } & \multicolumn{6}{|c|}{ Rapidly evolving genes } \\
\hline & & \multirow[t]{2}{*}{ Total } & \multirow{2}{*}{$\begin{array}{l}\text { Global } \\
\text { Neurospora }\end{array}$} & \multicolumn{4}{|l|}{ Branch specific } \\
\hline & & & & N. intermedia & N. crassa & N. discreta & N. tetrasperma \\
\hline Total & 988 & 204 & 164 & 49 & 41 & 135 & 21 \\
\hline Sexual & 99 & 26 & 19 & 7 & 4 & 22 & 1 \\
\hline Constitutive & 627 & 112 & 94 & 25 & 22 & 72 & 13 \\
\hline Vegetative & 94 & 15 & 9 & 2 & 2 & 11 & 1 \\
\hline $\mathrm{n} / \mathrm{a}^{\mathrm{b}}$ & 168 & 51 & 42 & 15 & 13 & 30 & 6 \\
\hline
\end{tabular}

${ }^{\mathrm{b}}$ genes for which data from the microarray analysis is lacking.

Both total number and the distribution of these genes in the global ratio model and all separate branches is shown. 


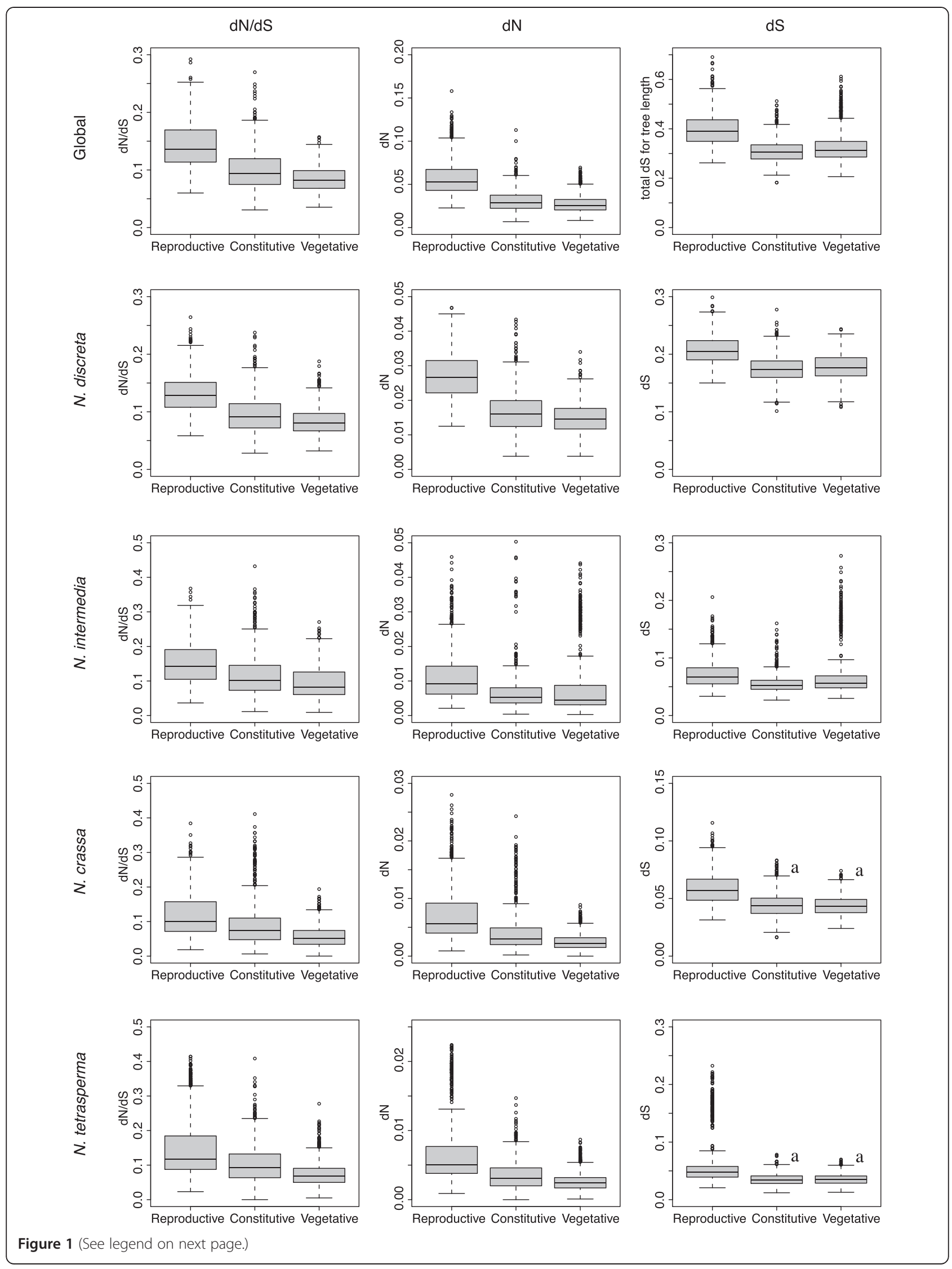


(See figure on previous page.)

Figure 1 Boxplots of the distribution of the estimates of $d N, d S$ and $d N / d S$ for the 1000 bootstrap replicates for each gene category. Data is shown for both the global estimate (one-ratio model in codeml) and for each separate branch (two-ratio model with the specified branch as foreground). Boxes represent the second and third quantile of the estimates and whiskers shows the lowest and highest estimates, excluding outliers. "a" indicates that the two distributions are not significantly different from each other. For all other comparisons $P<0.001$. Outliers are shown as circles.

gene categories (15 of 94: 16\%) (Table 1). However, the difference did not pass our criterion for statistical significance $(P=0.057)$. A high proportion of rapidly evolving genes were also found among the genes that were not well-measured on the microarray (51 of 168: 30\%) (Table 1), possibly explained by them being too diverged to adequately hybridize to the $N$. crassa oligonucleotide microarray.

The sex-associated genes evolve faster than vegetative and constitutively expressed genes

To assess whether genes in the sexual gene category evolved faster than the genes of the vegetative and constitutive gene categories, 1000 bootstrap replicates of $\mathrm{dN} / \mathrm{dS}$ values from a concatenated alignment of 10 randomly chosen genes from each gene category were run. The results are summarized in Table 2 and the distribution of the estimated $\mathrm{dN} / \mathrm{dS}, \mathrm{dN}$, and $\mathrm{dS}$ from the bootstrap analyses are shown as box plots in Figure 1. For both the global analysis and for each branch in the star phylogeny of the 4 species, the mean $\mathrm{dN} / \mathrm{dS}$ for the sexual gene category was higher than for the constitutive gene category, which in turn exhibited a higher mean estimate of $\mathrm{dN} / \mathrm{dS}$ than the vegetative gene category (Table 2). A Wilcoxon rank-sum test verified that the distributions of $\mathrm{dN} / \mathrm{dS}$ estimates for each gene category deviated significantly from each other for both the global model and for each branch separately $(P<0.001$, Figure 1$)$. The same pattern of sexual $>$ constitutive $>$ vegetative was revealed in examination of the estimated $\mathrm{dN}$, with one exception: in the $N$. intermedia branch, the mean of the vegetative gene category was higher than the mean for the constitutive gene category (Table 2). The median, however, was lowest for the vegetative gene category (Figure 1). The distribution of $\mathrm{dN}$ for each gene category (sexual, vegetative and constitutive, respectively) was significantly different from the distributions of $\mathrm{dN}$ for both other categories, as calculated for both the global and for each branch separately (Wilcoxon rank sum test, $P<0.001$ ).

In all analyses (global and per branch) the sexual gene category had a higher mean dS than the other categories, and the difference was statistically significant $(P<0.001$; Figure 1). For the global model, and the $N$. discreta and the $N$. intermedia branches, the mean dS of the vegetative category was higher than the constitutive category, and the two distributions were statistically significantly different $(P<0.001$, Wilcoxon rank sum test, Figure 1$)$. In the branches delineating $N$. crassa and $N$. tetrasperma, the vegetative $d S$ distribution did not differ significantly from that of the constitutive category (Figure 1).

In parallel, we performed the same analyses on the smaller subcategory of the sexual category, the "sexual $Q<0.1$ ". All distributions found to be statistically significantly different between the "sexual" category and any of the constitutive and vegetative categories were also found to be statistically significantly different for the "sexual $Q<0.1$ " category $(P<0.001)$ and the differences in mean were always in the same direction (higher for the "sexual $Q<0.1$ " than for the constitutive and vegetative). Thus, the false discovery rate cut off did not change our results.

\section{Annotation of rapidly evolving sex-associated genes}

Table 3 shows the 20 genes that were categorized as sexassociated, and that also had a higher than mean $\mathrm{dN} / \mathrm{dS}$ in the global analysis (19 genes) and/or in the N. intermedia branch analysis (1 unique gene). Of these "rapidly evolving sex-associated genes", 13 encode proteins that are similar (E-value $<1 \mathrm{e}-10)$ to proteins or domains with a characterized function (Table 3). Four hypothetical proteins were predicted to contain secretion signal peptides, transmembrane domains or GPI-anchors and 7

Table 2 Mean dN/dS of 1000 bootstrap replicates of 10 randomly chosen and concatenated genes for each gene category

\begin{tabular}{lcccc}
\hline & All genes (990) & Sexual (99) & Constitutive (628) & Vegetative (94) \\
\hline Global & 0.111 & 0.142 & 0.099 & 0.084 \\
N. intermedia & 0.125 & 0.151 & 0.115 & 0.098 \\
N. crassa & 0.102 & 0.120 & 0.088 & 0.058 \\
N. discreta & 0.106 & 0.131 & 0.096 & 0.084 \\
N. tetrasperma & 0.110 & 0.152 & 0.102 & 0.076 \\
\hline
\end{tabular}

The number of genes in each gene category is shown in parenthesis. 


\begin{tabular}{|c|c|c|c|}
\hline Gene & One ratio $\mathrm{dN} / \mathrm{dS}$ & Putative function/Conserved domains & E-value ${ }^{a}$ \\
\hline NCU01720 & 0.583 & Glycosyl hydrolase catalytic core protein & $2 \mathrm{e}-49$ \\
\hline NCU02916 & 0.233 & Endoglucanase II, glycosyl hydrolase family 61 & $1 e-94$ \\
\hline NCU03013 & 0.386 & Anchored cell wall protein-10, Cu,Zn-superoxide dismutase & $2 \mathrm{e}-44$ \\
\hline NCU03584 & 0.176 & Polyketide synthase & 0 \\
\hline NCU03861 & 0.245 & Glutaminase A & 0 \\
\hline NCU04034 & 0.261 & Hypothetical protein, 4 transmembrane domains & - \\
\hline NCU04628 & 0.442 & $\mathrm{C} 2 \mathrm{H} 2$-type zinc finger domain protein & $6 e-44$ \\
\hline NCU04645 & 0.178 & Hypothetical protein, DUF124 domain-containing protein & $5 e-45$ \\
\hline NCU04730 & 0.168 & Post-transcriptional silencing protein QDE-2 & 0 \\
\hline NCU05191 & 0.252 & Hypothetical protein, signal peptide, 2 transmembrane domains, GPI-anchor & - \\
\hline NCU05861 & 0.161 & NF-X1 finger and DNA/RNA helicase domain protein & 0 \\
\hline NCU06387 & 0.531 & Hypothetical protein & - \\
\hline NCU0731 b & 0.379 & Hypothetical protein, signal peptide, 3 transmembrane domains & - \\
\hline NCU07743 & 0.244 & Taurine catabolism dioxygenase TauD & $1 e-81$ \\
\hline NCU07888 & 0.198 & Pleckstrin homology domain-containing protein & $2 \mathrm{e}-40$ \\
\hline NCU08435 & 0.379 & RNA-dependent RNA polymerase & 0 \\
\hline NCU08986 & 0.257 & Hypothetical protein & - \\
\hline NCU09099 & 0.267 & Hypothetical protein, signal peptide, GPI-anchor & - \\
\hline NCU0935 $7^{c}$ & 0.349 & ATPase, DNA/RNA helicase, nonsense-mediated mRNA decay protein & 0 \\
\hline NCU09575 & 0.180 & Sterol esterase & 0 \\
\hline
\end{tabular}

${ }^{a}$ E-value originate from BLASTP analysis of NCBI nr database, or from the SMART protein analysis tool. E-values $>1 e-10$ are not reported.

${ }^{b}$ Candidate genes selected for further examination for site-specific positive selection by sequencing and analysis of additional heterothallic species of Neurospora.

c This gene only had a significantly higher than mean $\mathrm{dN} / \mathrm{dS}$ for the branch delineating $\mathrm{N}$. intermedia.

were classified as encoding hypothetical proteins because they displayed low similarity (E-value $\geq 1 \mathrm{e}-10$ ) to previously characterized proteins or domains (Table 3 ).

\section{Sites evolving under positive selection in candidate sex- associated genes}

To provide site-specific estimates of the evolutionary processes underlying the rapid evolution of five of our candidate fast-evolving sex-associated genes, we increased our statistical power by analyzing the genes from additional species of Neurospora (Additional file 2: Table S2), again applying the maximum likelihood program codeml included in the PAML package version $4.3[32,33]$. The five candidate genes were chosen from the list of rapidly evolving sex-associated genes (Table 3) based on their higher than mean $\mathrm{dN} / \mathrm{dS}$ and existence of suitable primer sites in the 4-way alignment. The additional taxon sampling yielded enough power to demonstrate that three of these genes, NCU03013, NCU06387, and NCU07311, contained up to three individual codons that have evolved under positive selection in Neurospora (Table 4). In NCU03013, putatively encoding a superoxide dismutase, the two positively selected sites $\mathrm{P}_{192}$ and $\mathrm{A}_{196}$ are located outside the Cu_Zn_Superoxide_Dismutase family module on the C-terminal side (Additional file 3: Figure S1). Both NCU06387 and NCU07311 are reported as conserved hypothetical proteins and no functional modules were found that can be correlated with the sites under positive selection. However, three transmembrane domains were identified in NCU07311 and two positively selected sites $\left(\mathrm{Y}_{119}\right.$ and $\left.\mathrm{A}_{126}\right)$ are located in a predicted extracellular loop and hence putatively exposed to the external environment (Additional file 3: Figure S1). For NCU01720 and NCU03584, we did not detect signs of positive selection at the level of individual codons (Table 4).

\section{Phylogenetic specificity and chromosomal locations of genes in different gene categories}

Rapid evolution of sex-associated genes would manifest as enrichment of genes in the sexual gene category among those that were found previously to be lineage specific. Correspondingly, vegetative and constitutive genes would be enriched among more phylogenetically conserved gene classes $[4,7,34]$. Thus, we investigated the proportions of the individual genes falling into different phylogenetic specificity classes (as defined in [35]), 
Table 4 Summary statistics and parameter estimates from analyses of positive selection for selected rapidly evolving sex-associated genes

\begin{tabular}{|c|c|c|c|c|c|c|c|c|c|c|}
\hline \multirow[t]{2}{*}{ Gene name } & \multirow[t]{2}{*}{ Number of taxa } & \multirow[t]{2}{*}{ Locus size $^{a}$} & \multirow[t]{2}{*}{ Model } & \multirow[t]{2}{*}{ Inl } & \multirow[t]{2}{*}{ p-value } & \multicolumn{3}{|l|}{ Estimated parameters } & \multirow[t]{2}{*}{ Mean dN/dS } & \multirow[t]{2}{*}{ Codons $^{\mathrm{b}}$} \\
\hline & & & & & & $\mathrm{dN} / \mathrm{dS}(\omega 0)$ & $\mathrm{dN} / \mathrm{dS}(\omega 1)$ & $\mathrm{dN} / \mathrm{dS}(\omega 2)$ & & \\
\hline \multirow[t]{4}{*}{ NCU01720 } & 12 & 273 & M1a & -1755.83 & & $\omega 0: 0.0296, p 0: 0.7505$ & $\omega 1: 1, p 1: 0.2495$ & & 0.272 & \\
\hline & & & M2a & -1755.47 & 0.7012 & $\omega 0: 0.0368$, p0: 0.7603 & $\omega 1: 1, p 1: 0.2373$ & $\omega 2: 35.1811, p 2: 0.0024$ & 0.349 & 0 \\
\hline & & & M7 & -1755.82 & & p: 0.0458 & q: 0.1244 & & 0.270 & \\
\hline & & & M8 & -1755.82 & 1.00 & p0: 0.8107 & p: 0.0591 , q: 0.5334 & $\omega: 1$ & 0.270 & 0 \\
\hline \multirow[t]{4}{*}{ NCU03013 } & 12 & 195 & M1a & -1298.67 & & $\omega 0: 0.0130$, p0: 0.7967 & $\omega 1: 1, p 1: 0.2033$ & & 0.214 & \\
\hline & & & M2a & -1290.09 & 0.0002 & $\omega 0: 0.0280$, p0: 0.8068 & $\omega 1: 1, p 1: 0.1769$ & $\omega 2: 10.1583, p 2: 0.0163$ & 0.365 & 2 \\
\hline & & & M7 & -1298.70 & & p: 0.0088 & q: 0.0284 & & 0.211 & \\
\hline & & & M8 & -1289.99 & 0.0002 & p0: 0.9834 & p: $0.0628, q: 0.2608$ & $\omega: 9.9750$ & 0.356 & 3 \\
\hline \multirow[t]{4}{*}{ NCU03584 } & 7 & 343 & M1a & -2157.94 & & $\omega 0:$ 0, p0: 0.8807 & $\omega 1: 1, p 1: 0.1193$ & & 0.119 & \\
\hline & & & M2a & -2157.20 & 0.4788 & $\omega 0:$ 0, p0: 0.8848 & $\omega 1: 1, p 1: 0.1014$ & $\omega 2: 3.1613$, p2: 0.0138 & 0.145 & 0 \\
\hline & & & M7 & -2158.31 & & p: 0.0064 & q: 0.0427 & & 0.102 & \\
\hline & & & M8 & -2157.38 & 0.3965 & p0: 0.8943 & p: 0.005, q: 1.9927 & $\omega: 1.3373$ & 0.141 & 0 \\
\hline \multirow[t]{4}{*}{ NCU06387 } & 12 & 407 & M1a & -3150.19 & & $\omega 0: 0.0779$, p0: 0.7367 & $\omega 1: 1, p 1: 0.2633$ & & 0.321 & \\
\hline & & & M2a & -3144.92 & 0.0051 & $\omega 0: 0.1610, \mathrm{p} 0: 0.8954$ & $\omega 1: 1, p 1: 0$ & $\omega 2: 2.4839, p 2: 0.1046$ & 0.404 & 0 \\
\hline & & & M7 & -3151.76 & & p: 0.0984 & q: 0.194 & & 0.336 & \\
\hline & & & M8 & -3144.94 & 0.0011 & p0: 0.8963 & p: 19.2341, q: 99 & $\omega: 2.4946$ & 0.404 & 2 \\
\hline \multirow[t]{4}{*}{ NCU07311 } & 11 & 174 & M1a & -1345.32 & & $\omega 0:$ 0, p0: 0.6612 & $\omega 1: 1, p 1: 0.3388$ & & 0.339 & \\
\hline & & & M2a & -1340.47 & 0.0078 & $\omega 0: 0.1134$, p0: 0.8530 & $\omega 1: 1, p 1: 0.0171$ & $\omega 2: 3.1712$, p2: 0.1299 & 0.526 & 1 \\
\hline & & & M7 & -1345.56 & & p: 0.0093 & q: 0.0189 & & 0.303 & \\
\hline & & & M8 & -1340.47 & 0.0061 & p0: 0.8661 & p: 3.8329, q: 27.2819 & $\omega: 3.1319$ & 0.525 & 3 \\
\hline
\end{tabular}

${ }^{a}$ Number of analyzed codons

'Number of positively selected codons identified with the models 
Table 5 Phylogenetic specificity of the genes in each gene category

\begin{tabular}{lllll}
\hline Phylogenetic class $^{1}$ & & Sexual & Constitutive & Vegetative \\
\hline Neurospora orphans & Obs & $100^{* * *}$ & 656 & 54 \\
& Exp & 67.3 & 664.7 & 77.9 \\
Pezizomycotina-specific & Obs & $206^{* *}$ & $1771^{* * *}$ & 117 \\
& Exp & 174.1 & 1718.5 & 201.4 \\
Ascomycota core & Obs 6 & 91 & 9 \\
Dikarya core & Exp & 8.8 & 87.0 & 10.2 \\
Eukaryote/Prokaryote core & Obs 77 & 1448 & $290^{* * *}$ \\
& Obs 68 & 582 & 73 \\
Other/unknown & Exp & 150.9 & 1489.5 & 174.6 \\
& Obs & $17 / 35$ & $90 / 387$ & $17 / 29$ \\
& Exp & $10.3 / 37.5$ & $101.8 / 370.1$ & $11.9 / 43.4$ \\
\hline
\end{tabular}

${ }^{1}$ Phylogenetic class from Kasuga et al. [35] are defined as the level of specificity in the tree of life at which homologues of the $\mathrm{N}$. crassa genes are found in genomes of other organisms.

${ }^{*} P<0.05,{ }^{* *} P<0.01,{ }^{* *} P<0.001$ : $p$-values for enriched classes are due to Fisher exact test with Benjamini and Hochberg multiple testing correction.

and found that they differed between the gene categories in line with these expectations (Table 5). Specifically, the two phylogenetically most specific classes, Neurospora orphans and Pezizomycotina-specific genes, were enriched $(P<0.01)$ for sex-associated genes, and the majority of the sex-associated genes $(60 \%)$ were found in these two classes (Table 5). Furthermore, the phylogenetically broadest gene class (the Eukaryote/Bacterial core) was enriched with genes within the vegetative category $(P<0.001$, Table 5). A noteworthy exception is that one of the more specific classes, the Pezizomycotina-specific class, was enriched with genes of the constitutive gene category $(P<0.001$, Table 5$)$. This result is not in accord with the expectation. Furthermore, for the subcategory "sexual $Q<0.1$ ", we did not find a statistically significant enrichment in any of the phylogenetic specificity classes, although the Neurospora orphans and Pezizomycotinaspecific genes together comprised the majority of the “sexual $Q<0.1$ ” genes (51\%).

When investigating the genomic distribution of genes of different categories, we found no statistically significant difference between observed and expected number for any of the gene categories on any of the chromosomes (Fisher's exact tests, $P>0.05$, data not shown). Furthermore, we did not find differences in codon usage between the gene categories (data not shown).

\section{Correlation between gene length, gene expression and evolutionary rate}

The distribution of per-gene estimates of mean absolute expression for the constitutive gene category $($ mean $=1089$, median $=365)$ was significantly different from the distribution for both the sexual $($ mean $=1703$, median $=536)$ and the vegetative $($ mean $=1202$, median $=546)$ categories (Wilcoxon rank sum test, $P<0.001$ ), while the distribution did not differ significantly between the sexual and vegetative categories $(P=0.13)$. However, we found no statistically significant correlations between the mean absolute expression for each gene and estimated global $\mathrm{dN} / \mathrm{dS}$; neither for all genes nor within each category $\left(R^{2} \leq 0.006\right.$, $P>0.05)$. The distribution of the length of the gene coding regions (CDS) based on N. crassa did not differ significantly between the gene categories (Wilcoxon rank sum test, $P>0.05$ ) and we found no significant correlations between CDS length and estimated global $\mathrm{dN} / \mathrm{dS}$, for either all genes or within each gene category $\left(R^{2}<0.003\right.$, $P>0.05$ ). Thus, the observed differences in $\mathrm{dN} / \mathrm{dS}$ cannot be explained by differences in protein length or absolute expression levels between genes of different categories.

\section{Discussion}

We have demonstrated that the previously observed pattern of high rates of evolution in reproductive genes extends to the fungal kingdom. Genes up-regulated during sexual reproductive stages in $N$. intermedia exhibited a higher mean $\mathrm{dN} / \mathrm{dS}$ than genes with relatively high expression in vegetative stages or genes that were constitutively expressed. Thus, the examples of rapidly evolving reproductive genes that were previously revealed in fungi $[12,15,18,19]$ can be considered components of a genome level phenomenon, in accordance with the pattern found in the animal kingdom $[1,3]$. To our knowledge, this study represents the first genome-scale demonstration of the overall rapid molecular evolution of sexassociated genes in a fungal system.

The sex-associated genes identified in this study exhibited higher mean $\mathrm{dN} / \mathrm{dS}$ than other genes, indicating rapid evolution on the protein level. The concatenated data from 4 species was sufficient to infer the overall evolution of gene categories, but to few taxa were sampled to infer specific codons evolving under positive selection [36]. To further analyze the basis of the higher $\mathrm{dN} / \mathrm{dS}$, we sequenced more taxa for five of the rapidly evolving sex-associated genes and demonstrated that three of these genes contain specific codons that have evolved under positive selection. Our results indicate that positive selection is indeed a factor driving the elevated rate of evolution of the sex-associated genes. However, for the majority of the genes in the sexual gene category, we could not distinguish between directional or stochastic processes as the reason for the increased divergence. For most individual genes identified as rapidly evolving, the estimated $\mathrm{dN} / \mathrm{dS}$ was below 1 , meaning they did not show a clear sign of positive selection averaged across sites. Due to the extensive functional 
constraints of most proteins, in most circumstances only a fraction of all codons in a gene can evolve under positive selection. Thus, genes with a high $\mathrm{dN} / \mathrm{dS}$ that deviates significantly from the mean are candidates for positive selection even if the $\mathrm{dN} / \mathrm{dS}$ is below 1 since the probability of positive selection acting on specific codons increases with higher overall $\mathrm{dN} / \mathrm{dS}$ estimates (e.g., [6]).

Although data from the five candidate genes suggest that positive selection is at least one of the factors leading to an elevated $\mathrm{dN} / \mathrm{dS}$ in sex-associated genes, a high $\mathrm{dN} / \mathrm{dS}$ may also be caused by relaxed selective constraints, and we cannot reject this factor as an alternative/additional cause of the elevated $\mathrm{dN} / \mathrm{dS}$ of the sexassociated genes observed in this study. First, a mutation that is not deleterious in one tissue may be deleterious in another, and hence selective constraints on a gene increase with the number of tissues where it is expressed. Relaxed selective constraints can thus be expected in genes with narrow domains [37], such as those for which expression is specific to the sexual stage in Neurospora. Second, one may speculate that Neurospora spends a relatively high proportion of its life cycle in vegetative growth [38] and that this leads to greater selective constraints on genes expressed in vegetative mycelia as compared to those induced during sexual reproduction. However, both alternative explanations for our results are contradicted by the finding that genes that are found in the constitutive gene category, i.e., genes with broadest function, do not show the lowest $\mathrm{dN} / \mathrm{dS}$.

In addition to a higher $\mathrm{dN} / \mathrm{dS}$, genes exhibiting relatively high expression in sexual tissue are characterized by both higher estimated $\mathrm{dN}$ and higher estimated $\mathrm{dS}$ compared with the constitutive and vegetative gene categories. These rates demonstrate that sex-associated genes are fast evolving at both non-synonymous and synonymous sites, a finding that is consistent with animal systems where high substitution rates in sex-associated genes are reported $[2,7]$. Variation in mutation rates, which results in variation of dS, is influenced by factors such as GC content, recombination rate, gene conversions and indel frequency $[39,40]$. Furthermore, a low dS as in the constitutive and vegetative gene categories can be caused by selection for preferred codons (codon bias) to ensure efficient and accurate translation in highly expressed genes [41-43], but we did not find general differences in codon usage between the gene categories. Interestingly, the dS is higher in the genes that are up-regulated in the vegetative tissue in our study compared to the constitutively expressed gene category (although we found no significant difference in the two shortest branches). Further analyses of mutation rate are needed in order to resolve the effect of mutation rate on $\mathrm{dS}$.

We found that the sex-associated genes are enriched in the two phylogenetically most specific gene groups (the Neurospora orphans and the Pezizomycotinaspecific genes [35]), indicating that they are overrepresented by novel, or ancient and highly divergent, genes. The enrichment of young genes is in line with studies on animals where sex-associated genes are found to show high levels of novelty as well as high birth and death rates $[4,7,34]$ and indicating an over-all rapid evolution of the sex-associated genes on the genome level. Further support of high levels of novelty in fungal sexassociated genes is provided by recent observations based on genomic comparison of yeasts: many genes essential for sexual reproduction in Saccharomyces cerevisiae seem to be absent in sexually reproducing Candida species $[20,21,44]$. Although the genes investigated in yeasts function in determining cell identity and during meiosis, thus presumably operating at different developmental stages than the genes investigated herein, our studies point in the direction of a high turnover of fungal genes involved in sexual reproductive processes. We note that $57 \%$ of the rapidly evolving sex-associated hypothetical proteins are predicted to be surface exposed due to the presence of secretion signal peptides, transmembrane domains, or GPI-anchors. This finding indicates that these proteins interact physically with extracellular proteins or substrates.

The wide array of rapidly evolving reproductive genes in animals and plants is generally explained by a set of different theories that include sexual selection (in the form of sperm competition, co-evolution of male and female genes caused by sexual conflict, female choice), self/non-self recognition to avoid inbreeding [1] and/or reinforcement of mating barriers between species [17]. In contrast to animals, reports on sexual selection in fungi are exceptional [45-47]. As a consequence, there is a general lack of knowledge of the effects of sexual selection in fungal biology, although recent evidence of both female choice and male-male competition has been shown in the basidiomycete Schizophyllum commune [45]. There is no inherent reason why sexual selection should not be applicable to the fungal kingdom, and we suggest that it plays a role in driving the observed divergence of the sex-associated genes in Neurospora. Indeed, the scarcity of studies demonstrating sexual selection in fungi may be attributable to the difficulty of observing the traits that are under selection: relevant traits are likely to be apparent only at cellular or subcellular levels.

While the male partner in Neurospora contributes solely with the fertilizing nucleus, the maternal parent is alone responsible for the allocation of resources to develop the fruiting body and ascospores. If the female is likely to make contact with more than one potential partner, the evolutionary cost of a bad choice can be severe, especially since a mycelium is inhibited from mating again after the mating process is completed $[26,48]$. 
Extensive crossing experiments performed with the aim of distinguishing between biological species of Neurospora $[25,49]$ demonstrate notable differences in mating success within species. One experiment has shown evidence of reinforced reproductive barriers between sympatric populations of $N$. crassa and $N$. intermedia $[25,26]$, in the form of earlier abortion of sexual development in hybrid crossings in sympatric populations compared to allopatric. The mechanism by which the hybrid crosses are aborted is unknown, but it seems to operate after mating and before karyogamy [25,26], which is the time span from which our sex-associated gene category was identified. Thus, the sex-associated genes identified in this study may be affected by female choice. In $\mathrm{Neu}$ rospora, there is neither sperm fluid nor specific male organs, and fertilization is possible by nuclear transfer from hyphal fragments acting as male fertilizing units. In addition, the expressed genes identified in the current study most likely originate from the female partner, due to heavy overrepresentation of protoperithecial tissue compared to the low amounts of cells in the conidial suspension used for fertilization. Nevertheless, until male and female tissues are analyzed separately, it is not possible to disentangle whether the higher rate of divergence observed in sex-associated genes in this study can be explained by male-specific rapid evolution.

The primary goal of this study was to test whether evolutionary rate differed in vegetative and sex-associated genes. Our result that sex-associated genes have evolved faster is robust to differing stringency of categorization based on the expression-data. Future studies may reveal the exact driving force and the functional consequences of the changes. Several recent studies indicate that initiation and development of the fungal fruiting body is a complex process that involves a specific regulatory program (e.g., [50-53]). Nevertheless, investigations of the processes underlying rapid evolution of sex-associated genes in fungi are severely hampered by the scarcity of functional studies of fungal mating. With the exception of mating-type genes [54], pheromones and their receptors [23,24,55], limited information is available about the proteins and genes involved in the mating process in Neurospora. Accordingly, functional data are lacking for the vast majority of the sex-associated genes investigated in this study, and they are solely identified based on the assessments of gene expression. This lack of annotation makes it probable that our recognized set of sex-associated genes contain some genes that are not important for mating. Additional experimentation is needed to confirm their importance in the sexual reproductive process in Neurospora. Moreover, our discretely staged experimental design makes it possible that some transiently expressed genes are missed. Nevertheless, in the literature we find phenotype data relating to sexual development for mutants of two of the rapidly evolving sex-associated genes, NCU04628 and NCU03584. NCU04628 is predicted to encode a C2H2type zinc finger protein, disruption of which results in abnormal development of perithecia and ascospores [56]. NCU035684 encodes a putative homolog to the Sordaria macrospora pks polyketide synthase gene. Disruption of this homolog in S. macrospora results in an albino phenotype and fragile, but viable, ascospores [57].

Microarray data was not well-measured for 169 of the genes with a 4-way alignment. The reason for the missing data may be sequence differences between $N$. intermedia and $N$. crassa that result in absence of signal during hybridization, which would result in absence of gene category data for the most rapidly evolving genes. This explanation is supported by the fact that we found the highest proportion of individual genes with a higher than mean $\mathrm{dN} / \mathrm{dS}$ in this group of genes. In addition, our criterion for construction of the 3-way and four-way alignments may have excluded the most divergent genes from our analyses. We cannot deduce whether the inclusion of these "invisible" orthologs in the analyses would have changed any of our results.

\section{Conclusion}

Taken together, this study extends the domain of the genome-wide pattern of rapidly evolving reproductive genes from animal systems to fungi. Our results demonstrate that positive selection is at least one of the factors driving this rapid evolution. Although the precise cause for positive selection of sex-associated genes in Neurospora is unknown, we speculate that it may be driven by natural or sexual selection. Sex-associated genes that are rapidly evolving between taxa are interesting as candidates for future studies as they may play a role in reproductive incompatibility between Neurospora species. Correspondingly, the finding that sympatric interspecies matings in Neurospora abort earlier than allopatric interspecies matings $[25,26]$ suggests that mate recognition genes are under selection; a pattern consistent with reinforcement of reproductive barriers [25,26]. Future studies addressing the functional roles of the identified genes during reproduction are needed in order to clarify the mechanisms that ultimately result in higher rate of change for sex-associated genes. This functional knowledge will enable us to investigate the generality of diverse theories proposed to explain the rapid evolution of sex-associated genes across kingdoms.

\section{Methods}

\section{Strains of Neurospora intermedia used in the study}

Two strains of Neurospora intermedia, FGSC 8782 and FGSC 8882, were used in this study. FGSC 8782 is of mating-type $a$ and was originally collected in Homestead, 
Florida, U.S.A., while FGSC 8882 is of mating-type $A$, and was collected in Puerto Cortes, Honduras. Both strains belong to the phylogenetic subgroup NiA of $\mathrm{N}$. intermedia [58]. The two strains are highly inter-fertile and originate from a population that shows reinforced reproductive isolation with sympatric strains of $N$. crassa [25]. In addition, we used representatives of twelve heterothallic (selfsterile) species and subspecies (Additional file 2: Table S2). All strains were obtained from the Fungal Genetics Stock Center (FGSC, University of Missouri, MO, USA).

\section{Preparation of vegetative and sexual tissue samples of Neurospora intermedia}

Cultures of $N$. intermedia for microarray analysis and EST sequencing were grown in 90-mm Petri dishes on solid synthetic crossing medium (SCM) [59] with $2 \%$ sucrose, covered by a layer of sterilized cellophane membrane, and in test tubes with Vogel's minimal medium [60] with $1.5 \%$ sucrose. Unless otherwise specified, cultures were grown at $25^{\circ} \mathrm{C}$.

The sexual sample was obtained by collecting tissue from reciprocal crosses between the two isolates. The strain to be the perithecial (maternal) parent of each cross was incubated on SCM until the Petri dish contained numerous protoperithecia (the unfertilized female reproductive structures; 11 days for FGSC 8782 and 13 days for FGSC 8882). For the production of conidia (the male fertilizing unit), each of the strains was grown on Vogel's media for 3 days at $37^{\circ} \mathrm{C}$. The conidia were collected with a spatula and suspended in water. The conidial concentration of the suspension was estimated by a hemacytometer and adjusted to 500,000 conidia per $\mathrm{mL}$. During fertilization, $0.5 \mathrm{~mL}$ of the suspension (about 250,000 conidia) was spread with a sterile glass spreader onto the Petri dish containing the maternal tissue of the opposite mating-type. Fertilization was performed by transferring conidia from the mat a strain (8782) to the Petri dish containing maternal tissue of the mat $A$ strain (8882), and vice versa, to produce two reciprocal crosses. After fertilization, the crosses were incubated in darkness until harvest. The sexual tissue was sampled at five different time points: 3, 12, 24, 36, and 48 hours after the conidial suspension was added. This time series had previously been verified by microscopy to represent tissue at the stage of development until karyogamy (i.e., presence of croziers [61]) under our growth conditions. At harvest, the tissue was scraped off the cellophane with a scalpel and collected in $1.5 \mathrm{ml}$ Eppendorf tubes. The developing perithecia of the harvested tissue were not separated from the surrounding hyphae, and thus, the sexual tissue contained a background level of vegetative tissue. Each tube was immediately snap frozen after harvest in liquid nitrogen and stored at $-70^{\circ} \mathrm{C}$. Samples (RNA or tissue, see below) from the 5 time points from the two strains were pooled in equal amount and constitute our sexual sample in subsequent microarray and EST-analyses.

The vegetative tissue of each strain was grown for three days on SCM in constant darkness. At the time of harvest, the mycelia were inspected under a dissecting microscope to verify absence of protoperithecia and conidia in the culture. Thus, the same media and culture conditions were used for sexual and vegetative tissues, and the developmental stage of the tissue was the only difference between them. The same method for harvesting was used as with the sexual tissue. A pooled sample of RNA or mycelia of the two strains was used as the vegetative sample in subsequent microarray and ESTanalyses, respectively (see below).

\section{RNA and CDNA processing}

We followed Clark et al. [62] for RNA and cDNA processing for the microarray study. Briefly, we extracted total RNA from $50-100 \mathrm{mg}$ portions of the tissue using the TRI REAGENT kit (Molecular Research Center, Inc. Cincinnati, $\mathrm{OH}$ ). The tissue was homogenized by grinding in a $7 \mathrm{~mL}$ Dounce glass tissue grinder and by using Qiagen Qiashredder columns (Qiagen, Chatsworth, CA). After extraction, equal amounts $(\mu \mathrm{g})$ of the total RNA from the sexual tissue of all five time-points from both strains were pooled together to constitute the sexual sample. For the vegetative sample, total RNA from mycelia of each strain was pooled in equal amounts. MRC oligo(dT)-Cellulose columns (Molecular Research Center, Inc. Cincinnati, $\mathrm{OH}$ ) were used for poly(A) + mRNA purification. Samples for each hybridization were independently subjected to reverse transcription using Superscript II reverse transcriptase (Invitrogen), $0.5 \mu \mathrm{g}$ oligo $(\mathrm{dT})$ primers (Invitrogen), and $2 \mu \mathrm{g}$ poly-A mRNA.

\section{Microarray hybridization}

The cDNA was coupled with $\mathrm{Cy} 3$ or Cy5 labeled probes (Amersham Biosciences, Uppsala, Sweden), then purified using the QIAquick PCR purification kit (Qiagen). Four competitive hybridizations, including two dye-swaps, were performed between cDNA of the sexual and vegetative samples. Hybridizations were made in the dark at $55^{\circ} \mathrm{C}$ for 16 hours. The microarrays used in this study $[28,63]$ were based on the genome sequence of Neurospora crassa, a close relative to $N$. intermedia. The whole-genome-spotted oligonucleotide microarray contained 9,826 open reading frames, each represented by a 70 mer oligonucleotide probe that was robotically printed on CMT-GAPS-aminopolysilane-coated glass slides (Corning, Corning, NY) at the Yale University Center for Genomics and Proteomics, following the procedure by Kasuga et al. [28]. The divergence between N. crassa and $N$. intermedia is very low, with the proportion of 
variable sites in coding regions of housekeeping genes being $1.2 \%$ [64]. Therefore, we considered this 70-mer array, designed from the N. crassa genome sequence, to be appropriate for the analyses of expression of $N$. intermedia isolates, especially when analyzing differences in relative expression between strains of $N$. intermedia and not between $N$. intermedia and $N$. crassa $[65,66]$.

\section{Microarray data acquisition and analysis}

An Axon GenePix 4000B microarray scanner was used to acquire a two-channel color image of the array fluorescence. The microarray spots were located by using the GenePix Pro 6.0 software package (Axon Instruments, Foster City, CA) together with the array list file [67]. Before data collection each microarray was manually screened and adjusted, and abnormal spots were excluded. We normalized the ratio results as in Townsend [68] using the online tool available at The Filamentous Fungal gene Expression Database [29,69]. A Bayesian Analyses of Gene Expression Levels (BAGEL) was performed using the software UBAGEL $3.6[30,31]$ on the normalized data. For each gene, the relative expression level and a credibility interval of $95 \%$ was calculated.

We used the results from the BAGEL analysis to categorize genes among three exclusive alternatives: sexual, vegetative and constitutive. The sexual gene category contains all genes that exhibited a statistically significantly $(P<0.05)$ higher expression in the sexual tissue relative to the vegetative. The vegetative category contains all genes that exhibited a statistically significant higher expression in the vegetative tissue compared to the sexual, and the constitutive category consisted of all genes that did not exhibit differential expression between the sexual and vegetative samples. Q-values were calculated from our $P$-values using the software QVALUE [70] with the default settings. $P<0.05$ corresponded to $Q<0.62$ for the sexual category genes, and corresponded to $Q<0.51$ for the vegetative category genes. Because the aim was to divide the genes into their most likely gene categories, the false discovery rate is not critical (inclusion of inappropriately classified genes would decrease effect size, and therefore be conservative). Nevertheless, we performed an additional analysis on a more strictly defined sexual gene category only including genes with $Q<0.10$. The $Q$-value cutoff of $Q<0.10$ was selected to minimize the false positives while still allowing enough genes in the category to convey statistical power in the analyses. We refer to this subdivision of the sexual category as the "sexual $Q<0.1$ ".

\section{cDNA-library construction and EST sequencing of Neurospora intermedia}

RNA extraction, subtractive cDNA library construction and EST sequencing were outsourced to Agencourt
Bioscience Corporation (Beverly, MA). Total RNA was extracted from both the vegetative and the sexual tissue (pooled in equal amounts from both strains at different time points, see above), by using the Agencourt RNAdvance Tissue Kit. A subtracted cDNA library, enriched for sequences of genes expressed in the sexual sample, was prepared by the Suppression Subtractive Hybridization method [71] in which the cDNA from the vegetative sample was used to subtract the genes shared by the two samples. In addition, a separate library was constructed from the vegetative sample. Sequence data was composed of 5,376 reads, sequenced by using ABI (Applied Biosystems) sequencing technology: 3,840 of which were from the subtracted sexual cDNA library (1,920 clones, sequenced in two directions) and 1,536 of which were sequenced from the vegetative library (768 clones, sequenced in two directions). Thus, 1,920 clones from the subtracted sexual cDNA library and 768 clones from the vegetative library were sequenced in both forward and reverse directions. The EST-data have been deposited in EMBL/NCBI's EST database, and are accessible through the accession number HE957083-HE961812.

\section{EST data assembly}

The ESTs were processed and assembled de novo with the $\mathrm{phred} / \mathrm{crossmatch} / \mathrm{phrap}$ toolchain [72,73]. Basecalling, quality filtering and trimming was carried out with phred v0.071220.b using the default quality cutoff settings, after which crossmatch v1.090518 was used to screen out remaining vectors using the UniVec database [74]. Phrap was used to assemble the sequence with overlapping regions into contiguous sequences referred to here as Phrap contigs. After filtering and assembly, the data consisted of 4,984 reads.

\section{Three-way alignments of publicly available Neurospora sequences}

The 3-way alignments were generated from $N$. crassa [75], N. discreta [76] and N. tetrasperma (version 1 $[77,78]$ ) by using the SYNERGY algorithm [79], which identifies orthologs based on the sequence similarity from pair-wise BLAST of each proteome (expectation cutoff $<1 \mathrm{E}-5$ ) and synteny of loci across the 3 genomes. In total, a 3-way alignment was completed for 5,635 individual genes that were found to be unambiguously orthologous among the 3 species (Stajich et al., unpublished), corresponding to roughly half of the genes in the N. crassa genome.

\section{Orthology search for the Neurospora intermedia sequences}

A BLAST database [80] was built from the 3-way alignments and the $N$. crassa genome (downloaded on April 13, 2011) and served as reference for establishing 
orthology for the new and pre-processed $N$. intermedia sequence reads. Gene IDs were assigned to the $N$. intermedia reads by running megaBLAST [81] queries against the 3-way database. The queries were configured to use a length cutoff of 100 aligned bases to register a match. Of the 4,984 reads retained after assembly, megaBLAST against the 3-way database identified 2,573 reads as usable, corresponding to only a single gene target. By running BLAST on the Phrap-generated contigs built from the total read pool, 104 additional reads were identified, and finally, 188 reads were unambiguously identified using the less stringent BLASTN algorithm and an alignment cutoff at 60 bases. The 1,939 remaining sequence reads were not used in the subsequent analyses, but were run in BLAST against the $N$. crassa genome to provide additional gene statistics using the same algorithms, prioritizing megaBLAST hits over BLASTN hits. In total, 4,585 of the $N$. intermedia reads yielded a BLAST-hit to any of $1,392 N$. crassa genes.

\section{Adjustments of the 4-way alignments}

A custom pipeline was written in Bash/Perl to assemble the identified $N$. intermedia data and align it to the three-way alignments on a gene-by-gene basis. For each of the genes in the 3-way set, we used BLAST to find the best Phrap contig and unassembled singlets to establish direction and alignable boundaries. These cues were used to identify local subalignments against which each Phrap product could be aligned using the G-INS-i algorithm and seed method in MAFFT [82,83]. Frameshifting inserts were filtered out and incomplete codons or premature stop codons were masked as missing data. The aligned $N$. intermedia data was merged into a single consensus sequence. In cases where aligned fragments were overlapping but had not been assembled into a contig by Phrap, remaining sequence length and contig size were used as tokens of sequence quality to resolve which fragment the consensus should be based on. Finally, the new four-way alignment was filtered so that only gap-less codon positions with data from all four species were included in downstream analyses. The program Gblocks [84] was used to remove poorly aligned regions before further analyses.

\section{Identification of rapidly evolving genes}

To identify rapidly evolving genes in Neurospora, we invoked two global ratio models using the maximum likelihood program codeml, included in the PAML package version 4.3 [32,33]: one in which the global $\mathrm{dN} / \mathrm{dS}$ was estimated as a free parameter, and one in which it was fixed to the mean $\mathrm{dN} / \mathrm{dS}$ for all genes. The mean $\mathrm{dN} / \mathrm{dS}$ was estimated by running the codeml analysis on a concatenated alignment of all 4-way orthologous gene alignments. These two models are nested, and differ in one estimated parameter, so a log-likelihood ratio test (LRT) with one degree of freedom was used to to evaluate the fit to the data for the two models, and thereby identify genes with a $\mathrm{dN} / \mathrm{dS}$ significantly deviating from the mean. In the phylogeny of the four taxa included in the analyses, $N$. discreta represents the most ancestral branch, but the phylogenetic relationship is not fully resolved for the other three taxa [58]. Thus, we used a completely unresolved star tree as an unrooted input phylogeny for the analyses.

To test for branch-specific rapidly evolving genes, i.e., genes evolving rapidly in the branches delineating $N$. intermedia, $N$. crassa, $N$. discreta or $N$. tetrasperma, we used the same approach but with the two-ratio model specifying the branch of interest as foreground and comparing the log-likelihood value with the value for the model where the foreground branch $\mathrm{dN} / \mathrm{dS}$ was fixed at the mean for that branch. To adjust for multiple testing, $Q$-values were calculated from our $P$-values using the software QVALUE [70] and $Q<0.05$ was considered significant.

\section{Estimating global and branch-specific dN/dS for gene categories}

To estimate the mean $\mathrm{dN}, \mathrm{dS}$, and $\mathrm{dN} / \mathrm{dS}$ for each gene category distinguished by the microarray experiment (constitutive, sexual and vegetative) we implemented a bootstrap approach. For each bootstrap replicate, 10 randomly chosen genes were concatenated. The concatenation procedure was performed to overcome the uncertainty of the estimates typical for short sequences. On each concatenated alignment, we ran both the global ratio model and the four versions of the two-ratio models: one for each branch specified as the foreground branch. For each gene category, 1000 bootstrap replicates were performed, and the mean for the obtained estimates was calculated for each category. To test for differences in the distribution of the estimates for $\mathrm{dN}$, $\mathrm{dS}$ and $\mathrm{dN} / \mathrm{dS}$ between the different categories, a Wilcoxon rank sum test with continuity correction, as implemented in $\mathrm{R}$, was performed, and $P$-values were adjusted for multiple testing using the method described by Benjamini and Hochberg [85]. In addition, these analyses were performed on the small subset consisting of 26 sexual genes falling into the category "sexual $Q<0.1$ ".

\section{PCR amplification and sequencing of candidate genes for positive selection}

Strains for PCR and sequencing (Additional file 2: Table S2) were grown in test tubes with Vogel's minimal medium with $1.5 \%$ sucrose [60] and DNA was extracted as in Karlsson et al. [15]. Primers for selected genes were designed based on homologous regions of the 4-way alignment, and are given in Additional file 4: Table S3. PCRs 
were performed using the Expand High Fidelity PCR System (Roche Applied Science, Indianapolis, USA). PCR products were purified with ExoSAP-IT reagent (Amersham Biosciences, Uppsala, Sweden). Sequencing was performed using the BigDye Terminator v3.1 Cycle Sequencing Kit (Applied Biosystems, Foster City, USA). The products were cleaned using BigDye XTerminator Purification Kit (Applied Biosystems), and then sequenced on an ABI3730XL (Applied Biosystems). The raw sequences were edited using the software package Sequencher 4.1.4 (Gene Codes Corporation, Ann Arbor, USA). The sequence alignments for each gene were adjusted manually using BioEdit version 7.0.0 [86].

\section{Analyses of positive selection of candidate genes}

To test if the higher than mean $\mathrm{dN} / \mathrm{dS}$ estimates for individual sex-associated genes might be caused by positive selection on individual sites within genes, we chose five genes for additional analysis among a larger set of species, ranging from seven to twelve taxa for the different genes (Additional file 2: Table S2). The genes were selected from the list of rapidly evolving sexassociated genes based on their high $\mathrm{dN} / \mathrm{dS}$ and the existence of suitable primer sites in the 4-way alignment. To evaluate the selective constraints acting on individual codon sites, we ran four models in the PAML package version 4.3 [32,33]: M1a, M2a, M7 and M8. The models constitute two nested pairs (M1a + M2a and M7 + M8) with one model of each pair only containing site classes allowing $\mathrm{dN} / \mathrm{dS}$ to vary between 0 and 1 (neutral models; M1a and M7), while the second model of each pair (selection models; M2a and M8) contains an additional site class in which $\mathrm{dN} / \mathrm{dS} \geq 1$, thus allowing positive selection. We based the analysis on the phylogeny of the heterothallic Neurospora from Dettman et al. [58]. Before the analysis, we excluded intronic sequences from the alignments and regions for which sequence data for less than half of the taxa were available. The Bayes empirical Bayes (BEB) calculation of posterior probabilities for site classes implemented in model M2a and M8 was used to identify codons likely to have evolved under positive selection [87].

\section{Functional annotation of rapidly evolving sex-associated genes}

Sex-associated genes identified to be rapidly evolving in the global model or in the $N$. intermedia-branch were individually studied. Translated amino acid sequences were analyzed with BLAST at NCBI and for conserved domains using the SMART protein analysis tool [88]. SignalP 3.0 [89] was used to search for signal peptide cleavage sites, and the big-PI Fungal Predictor program [90] was used to search for GPI-anchor sequences.

\section{Statistical analyses of gene category characters}

We investigated the phylogenetic distribution and chromosomal location of the genes of each gene category. The phylogenetic distribution for individual genes was taken from Kasuga et al. [35], which divided annotated protein coding genes from $N$. crassa into phylogenetic specificity classes depending on the phylogenetic relatedness in the tree of life of organisms with homologues of the gene. The chromosomal location was based on the annotation of the N. crassa genome ([75] downloaded on March 15, 2011). Over- and under-representation, for both phylogenetic distribution and chromosomal location, across the gene categories, were assessed using Fisher's exact test. $P$-values were adjusted for multiple testing using the method described by Benjamini and Hochberg [85] as implemented in R. We used the significance level of $P<0.05$.

Differences in codon usage between the gene categories was analyzed by performing multivariate (correspondence) analysis using the program CodonW version 1.4.4 (http://codonw.sourceforge.net/). The analysis was performed on the $N$. crassa gene sequences from the four taxon alignments used in the $\mathrm{dN} / \mathrm{dS}$ analysis. Codon usage for gene categories was visualized by plotting the position of each gene on the resulting correspondence analysis axis 1 and 2 .

\section{Correlation between gene expression, gene length and evolutionary rate}

Absolute expression for each gene was estimated by calculating the mean of the background-subtracted foreground intensity of the well-measured spots on the microarray [68]. For genes within the sexual and the vegetative gene categories the absolute expression means were calculated on the expression in the specific tissue types only. The mean for each gene in the constitutive category and the estimate for all genes were estimated from all measurements of expression for each gene. To test for differences in the distribution of the per-gene expression between the different categories, a Wilcoxon rank sum test with continuity correction, as implemented in R, was performed. Linear regression was used to calculate the per-gene association between absolute expression and estimated global $\mathrm{dN} / \mathrm{dS}$, and between CDS length of $N$. crassa and estimated global $\mathrm{dN} / \mathrm{dS}$ for each gene category and for the complete dataset. The linear regression analyses were performed in $\mathrm{R}$.

\section{Additional files}

Additional file 1: Table S1. A list of rapidly evolving genes, and the branch(es) in which a dN/dS higher than mean are found.

Additional file 2: Table S2. Candidate genes used to test for positive selection, and ID of additional heterothallic Neurospora strains sequenced. 
Additional file 3: Figure S1. Nucleotide and amino acid alignments of the three genes NCU03013, NCU06387, and NCU07311, showing which codons were found to evolve under positive selection.

Additional file 4: Table S3. Primers used for PCR amplification of candidate genes for test for positive selection

\section{Competing interests}

The authors declare that they have no competing interest

\section{Authors' contributions}

KN participated in the design of the study, performed the majority of the laboratory work, performed the evolutionary analyses and drafted the manuscript. AW participated in the data assembly and bioinformatics work. NS participated in the laboratory work and data analyses. JS participated in the sequence alignment. JPT contributed reagents, analytical advice, and assisted in drafting the manuscript. MK participated in the design of the study, data analyses and drafting of the manuscript. $\mathrm{HJ}$ conceived of the study, participated in study design, coordination, and in drafting the manuscript. All authors read and approved the final manuscript.

\section{Acknowledgements}

The authors acknowledge Dave Jacobson, Eric Bastiaans, Zheng Wang, and Aleksandra Adomas for quidance in the laboratory, Yu Sun for computational assistance, and Alexandra Mushegian for valuable comments on the manuscript. Pádraic Corcoran and Jennifer Anderson are acknowledged for proofreading the English of the manuscript. The Joint Genome Institute of US Department of Energy provided early access to the N. tetrasperma and $N$. discreta genomes. Funding from the Nilsson-Ehle donations, The Lars Hierta Memorial Foundation and Helge Ax:son Johnsons Stiftelse to Kristiina Nygren, and from The Swedish Foundation for International Cooperation in Research and Higher Education (STINT) and the Swedish Research Council to Hanna Johannesson, is greatly acknowledged.

\section{Author details}

${ }^{1}$ Department of Forest Mycology and Plant Pathology, Swedish University of Agricultural Sciences, Box 7026, SE-75007, Uppsala, Sweden. ${ }^{2}$ Department of Medical Biochemistry and Microbiology, Uppsala University, Box 582, SE-751, Uppsala, Sweden. ${ }^{3}$ Department of Plant Pathology and Microbiology, University of California at Riverside, 900 University Avenue, Riverside, CA 92521, USA. ${ }^{4}$ Department of Ecology and Evolutionary Biology, Yale University, 165 Prospect St., New Haven, CT 06520-8106, USA. ${ }^{5}$ Department of Evolutionary Biology, Evolutionary Biology Centre, Uppsala University, Norbyvägen 18 D, SE-752 36, Uppsala, Sweden.

Received: 3 May 2012 Accepted: 21 November 2012 Published: 27 November 2012

\section{References}

1. Clark NL, Aagaard JE, Swanson WJ: Evolution of reproductive proteins from animals and plants. Reproduction 2006, 131:11-22.

2. Singh RS, Kulathinal RJ: Sex gene pool evolution and speciation: A new paradigm. Genes Genet Syst 2000, 75:119-130

3. Swanson WJ, Vacquier VD: The rapid evolution of reproductive proteins. Nat Rev Genet 2002, 3:137-144.

4. Haerty W, Jagadeeshan S, Kulathinal RJ, Wong A, Ravi Ram K, Sirot LK, Levesque L, Artieri CG, Wolfner MF, Civetta A, Singh RS: Evolution in the fast lane: rapidly evolving sex-related genes in Drosophila. Genetics 2007, 177:1321-1335.

5. Nielsen R, Bustamante C, Clark AG, Glanowski S, Sackton TB, Hubisz MJ, Fledel-Alon A, Tanenbaum DM, Civello D, White TJ, et al: A scan for positively selected genes in the genomes of humans and chimpanzees. PLOS Biol 2005, 3:976-985.

6. Swanson WJ, Wong A, Wolfner MF, Aquadro CF: Evolutionary expressed sequence tag analysis of Drosophila female reproductive tracts identifies genes subjected to positive selection. Genetics 2004, 168:1457-1465.

7. Walters JR, Harrison RG: Combined EST and proteomic analysis identifies rapidly evolving seminal fluid proteins in Heliconius butterflies. Mol Biol Evol 2010, 27:2000-2013.
8. Fiebig A, Kimport R, Preuss D: Comparisons of pollen coat genes across Brassicaceae species reveal rapid evolution by repeat expansion and diversification. Proc Natl Acad Sci USA 2004, 101:3286-3291.

9. Ikeda K, Igic B, Ushijima K, Yamane H, Hauck NR, Nakano R, Sassa H, lezzoni AF, Kohn JR, Tao R: Primary structural features of the $S$ haplotype-specific F-box protein, SFB, in Prunus. Sex Plant Reprod 2004, 16:235-243.

10. Armbrust EV, Galindo HM: Rapid evolution of a sexual reproduction gene in centric diatoms of the genus Thalassiosira. Appl Environ Microb 2001, 67:3501-3513

11. Ferris PJ, Pavlovic C, Fabry S, Goodenough UW: Rapid evolution of sexrelated genes in Chlamydomonas. Proc Natl Acad Sci USA 1997, 94:8634-8639.

12. Pöggeler S: Phylogenetic relationships between mating-type sequences from homothallic and heterothallic ascomycetes. Curr Genet 1999, 36:222-231.

13. Clark NL, Swanson WJ: Pervasive adaptive evolution in primate seminal proteins. PLoS Genet 2005, 1:e35.

14. Finn S, Civetta A: Sexual selection and the molecular evolution of ADAM proteins. J Mol Evol 2010, 71:231-240.

15. Karlsson M, Nygren K, Johannesson $\mathrm{H}$ : The evolution of the pheromonal signal system and its potential role for reproductive isolation in heterothallic Neurospora. Mol Biol Evol 2008, 25:168-178.

16. Swanson WJ, Nielsen R, Yang Q: Pervasive adaptive evolution in mammalian fertilization proteins. Mol Biol Evol 2003, 20:18-20.

17. Howard DJ: Conspecific sperm and pollen precedence and speciation. Annu Rev Ecol Syst 1999, 30:109-132.

18. Martin SH, Wingfield BD, Wingfield MJ, Steenkamp ET: Causes and consequences of variability in peptide mating pheromones of ascomycete fungi. Mol Biol Evol 2011, 28:1987-2003.

19. Wik L, Karlsson M, Johannesson $\mathrm{H}$ : The evolutionary trajectory of the mating-type (mat) genes in Neurospora relates to reproductive behavior of taxa. BMC Evol Biol 2008, 8:109.

20. Butler G, Rasmussen MD, Lin MF, Santos MA, Sakthikumar S, Munro CA Rheinbay E, Grabherr M, Forche A, Reedy JL, et al: Evolution of pathogenicity and sexual reproduction in eight Candida genomes. Nature 2009, 459:657-662.

21. Lee SC, Ni M, Li W, Shertz C, Heitman J: The evolution of sex: a perspective from the fungal kingdom. Microbiol Mol Biol Rev 2010, 74:298-340.

22. Bistis GN: Evidence for diffusible, mating-type-specific trichogyne attractants in Neurospora crassa. Exp Mycol 1983, 7:292-295.

23. Kim H, Borkovich KA: Pheromones are essential for male fertility and sufficient to direct chemotropic polarized growth of trichogynes during mating in Neurospora crassa. Eukaryot Cell 2006, 5:544-554.

24. Kim H, Borkovich KA: A pheromone receptor gene, pre-1, is essential for mating type-specific directional growth and fusion of trichogynes and female fertility in Neurospora crassa. Mol Microbiol 2004, 52:1781-1798.

25. Dettman JR, Jacobson DJ, Turner E, Pringle A, Taylor JW: Reproductive isolation and phylogenetic divergence in Neurospora: comparing methods of species recognition in a model eukaryote. Evolution 2003, 57:2721-2741.

26. Turner E, Jacobson DJ, Taylor JW: Reinforced postmating reproductive isolation barriers in Neurospora, an Ascomycete microfungus. J Evol Biol 2010, 23:1642-1656.

27. Turner E, Jacobson DJ, Taylor JW: Genetic architecture of a reinforced, postmating, reproductive isolation barrier between Neurospora species indicates evolution via natural selection. PLoS Genet 2011, 7:e1002204.

28. Kasuga T, Townsend JP, Tian CG, Gilbert LB, Mannhaupt G, Taylor JW, Glass $\mathrm{NL}$ : Long-oligomer microarray profiling in Neurospora crassa reveals the transcriptional program underlying biochemical and physiological events of conidial germination. Nucleic Acids Res 2005, 33:6469-6485

29. Zhang Z, Townsend JP: The filamentous fungal gene expression database (FFGED). Fungal Genet Biol 2010, 47:199-204.

30. Townsend JP: Resolution of large and small differences in gene expression using models for the Bayesian analysis of gene expression levels and spotted DNA microarrays. BMC Bioinforma 2004, 5:54.

31. Townsend JP, Hartl DL: Bayesian analysis of gene expression levels: statistical quantification of relative mRNA level across multiple strains or treatments. Genome Biol 2002, 3:RESEARCH0071.

32. Yang Z: PAML: a program package for phylogenetic analysis by maximum likelihood. Comput Appl Biosci 1997, 13:555-556. 
33. Yang Z: PAML 4: phylogenetic analysis by maximum likelihood. $\mathrm{Mol}$ Biol Evol 2007, 24:1586-1591.

34. Tian X, Pascal G, Fouchecourt S, Pontarotti P, Monget P: Gene birth, death and divergence: The different scenarios of reproduction-related gene evolution. Biol Reprod 2009, 80:616-621.

35. Kasuga T, Mannhaupt G, Glass NL: Relationship between phylogenetic distribution and genomic features in Neurospora crassa. PLoS One 2009, 4:e5286.

36. Anisimova M, Bielawski JP, Yang Z: Accuracy and power of the likelihood ratio test in detecting adaptive molecular evolution. Mol Biol Evol 2001, 18:1585-1592.

37. Khaitovich P, Enard W, Lachmann M, Paabo S: Evolution of primate gene expression. Nat Rev Genet 2006, 7:693-702.

38. Tsai IJ, Bensasson D, Burt A, Koufopanou V: Population genomics of the wild yeast Saccharomyces paradoxus: Quantifying the life cycle. Proc Natl Acad Sci USA 2008, 105:4957-4962.

39. Ananda G, Chiaromonte F, Makova KD: A genome-wide view of mutation rate co-variation using multivariate analyses. Genome Biol 2011, 12:R27.

40. Baer CF, Miyamoto MM, Denver DR: Mutation rate variation in multicellular eukaryotes: causes and consequences. Nat Rev Genet 2007, 8:619-631.

41. Duret L: tRNA gene number and codon usage in the $C$. elegans genome are co-adapted for optimal translation of highly expressed genes. Trends Genet 2000, 16:287-289.

42. Duret L, Mouchiroud D: Expression pattern and, surprisingly, gene length shape codon usage in Caenorhabditis, Drosophila, Arabidopsis. Proc Natl Acad Sci USA 1999, 96:4482-4487.

43. Stoletzki N, Eyre-Walker A: Synonymous codon usage in Escherichia coli: selection for translational accuracy. Mol Biol Evol 2007, 24:374-381.

44. Reedy JL, Floyd AM, Heitman J: Mechanistic plasticity of sexual reproduction and meiosis in the Candida pathogenic species complex. Curr Biol 2009, 19:891-899.

45. Nieuwenhuis BP, Debets AJ, Aanen DK: Sexual selection in mushroomforming basidiomycetes. Proc Biol Sci 2011, 278:152-157.

46. Pringle A, Taylor JW: The fitness of filamentous fungi. Trends Microbiol 2002, 10:474-481.

47. Rogers DW, Greig D: Experimental evolution of a sexually selected display in yeast. $P$ R SOC B 2009, 276:543-549.

48. Howe HB, Prakash V: A Regulatory system controlling inhibition in sexual cycle of Neurospora. Can J Genet Cytol 1969, 11:689-705.

49. Menkis A, Bastiaans $E_{1}$ Jacobson DJ, Johannesson H: Phylogenetic and biological species diversity within the Neurospora tetrasperma complex. J Evol Biol 2009, 22:1923-1936.

50. Adomas AB, Lopez-Giraldez F, Clark TA, Wang Z, Townsend JP: Multitargeted priming for genome-wide gene expression assays. BMC Genomics 2010, 11:477.

51. Kim H, Nelson MA: Molecular and functional analyses of poi-2, a novel gene highly expressed in sexual and perithecial tissues of Neurospora crassa. Eukaryot Cell 2005, 4:900-910.

52. Nowrousian M: A novel polyketide biosynthesis gene cluster is involved in fruiting body morphogenesis in the filamentous fungi Sordaria macrospora and Neurospora crassa. Curr Genet 2009, 55:185-198.

53. Nowrousian M, Piotrowski M, Kuck U: Multiple layers of temporal and spatial control regulate accumulation of the fruiting body-specific protein APP in Sordaria macrospora and Neurospora crassa. Fungal Genet Biol 2007, 44:602-614.

54. Ferreira AVB, An ZQ, Metzenberg RL, Glass NL: Characterization of mat A-2, mat A-3 and Delta matA mating-type mutants of Neurospora crassa. Genetics 1998, 148:1069-1079.

55. Kim H, Metzenberg RL, Nelson MA: Multiple functions of $m f a-1$, a putative pheromone precursor gene of Neurospora crassa. Eukaryot Cell 2002, 1:987-999.

56. Colot HV, Park G, Turner GE, Ringelberg C, Crew CM, Litvinkova L, Weiss RL, Borkovich KA, Dunlap JC: A high-throughput gene knockout procedure for Neurospora reveals functions for multiple transcription factors. Proc Natl Acad Sci USA 2006, 103:10352-10357.

57. Engh I, Nowrousian M, Kuck U: Regulation of melanin biosynthesis via the dihydroxynaphthalene pathway is dependent on sexual development in the ascomycete Sordaria macrospora. FEMS Microbiol Lett 2007, 275:62-70.
58. Dettman JR, Jacobson DJ, Taylor JW: A multilocus genealogical approach to phylogenetic species recognition in the model eukaryote Neurospora. Evolution 2003, 57:2703-2720

59. Westergaard M, Mitchell HK: Neurospora V. A synthetic medium favoring sexual reproduction. Am J Bot 1947, 34:573-577.

60. Vogel: A convenient growth medium for Neurospora (medium N). Microbiol Genet Bull 1956, 13:42-43.

61. Read ND, Beckett A: Ascus and ascospore morphogenesis. Mycol Res 1996, 100:1281-1314.

62. Clark TA, Guilmette JM, Renstrom D, Townsend JP: RNA extraction, probe preparation, and competitive hybridization for transcriptional profiling using Neurospora crassa long-oligomer DNA microarrays. Fungal Genetics Reports 2008, 55:18-28

63. Dunlap JC, Borkovich KA, Henn MR, Turner GE, Sachs MS, Glass NL, McCluskey K, Plamann M, Galagan JE, Birren BW, et al: Enabling a community to dissect an organism: overview of the Neurospora functional genomics project. Adv Genet 2007, 57:49-96.

64. Nygren K, Strandberg R, Wallberg A, Nabholz B, Gustafsson T, Garcia D, Cano J, Guarro J, Johannesson H: A comprehensive phylogeny of Neurospora reveals a link between reproductive mode and molecular evolution in fungi. Mol Phylogenet Evol 2011, 59:649-663.

65. Oshlack A, Chabot AE, Smyth GK, Gilad Y: Using DNA microarrays to study gene expression in closely related species. Bioinformatics 2007, 23:1235-1242.

66. Renn SCP, Aubin-Horth N, Hofmann HA: Biologically meaningful expression profiling across species using heterologous hybridization to a cDNA microarray. BMC Genomics 2004, 5:42

67. Yale microarray experimental design, home of the filamentous fungal microarray database. http://www.yale.edu/townsend/Links/ffdatabase/ downloads.html.

68. Townsend JP: Multifactorial experimental design and the transitivity of ratios with spotted DNA microarrays. BMC Genomics 2003, 4:41.

69. The filamentous fungal gene expression database. http://bioinfo.townsend yale.edu/online.jsp.

70. Storey JD, Tibshirani R: Statistical significance for genomewide studies. Proc Natl Acad Sci USA 2003, 100:9440-9445

71. Diatchenko L, Lau YF, Campbell AP, Chenchik A, Mogadam F, Huang B, Lukyanov S, Lukyanov K, Gurskaya N, Sverdlov ED, Siebert PD: Suppression subtractive hybridization: a method for generating differentially regulated or tissue-specific cDNA probes and libraries. Proc Natl Acad SCl USA 1996, 93:6025-6030

72. Ewing B, Green P: Base-calling of automated sequencer traces using phred. II. Error probabilities. Genome Res 1998, 8:186-194.

73. Ewing B, Hillier L, Wendl MC, Green P: Base-calling of automated sequencer traces using phred. I. Accuracy assessment. Genome Res 1998 8:175-185.

74. The UniVec database. http://www.ncbi.nlm.nih.gov/VecScreen/UniVec.html.

75. Neurospora crassa database, Broad Institute. http://www.broadinstitute.org/ annotation/genome/neurospora/MultiHome.html.

76. JGl, Neurospora discreta FGSC 8579 mat A. http://genome.jgi-psf.org/Neudi1/ Neudi1.home.html

77. JGl, Neurospora tetrasperma FGSC 2508 mat A. http://genome.jgi-psf.org/ Neute1/Neute1.home.html.

78. Ellison CE, Stajich JE, Jacobson DJ, Natvig DO, Lapidus A, Foster B, Aerts A, Riley R, Lindquist EA, Grigoriev IV, Taylor JW: Massive changes in genome architecture accompany the transition to self-fertility in the filamentous fungus Neurospora tetrasperma. Genetics 2011, 189:55-69.

79. Wapinski I, Pfeffer A, Friedman N, Regev A: Automatic genome-wide reconstruction of phylogenetic gene trees. Bioinformatics 2007, 23:i549-i558.

80. Altschul SF, Gish W, Miller W, Myers EW, Lipman DJ: Basic Local Alignment Search Tool. J Mol Biol 1990, 215:403-410

81. Zhang Z, Schwartz S, Wagner L, Miller W: A greedy algorithm for aligning DNA sequences. J Comput Biol 2000, 7:203-214.

82. Katoh $\mathrm{K}$, Asimenos $\mathrm{G}$, Toh H: Multiple alignment of DNA sequences with MAFFT. Methods Mol Biol 2009, 537:39-64.

83. Katoh $\mathrm{K}$, Toh H: Improved accuracy of multiple ncRNA alignment by incorporating structural information into a MAFFT-based framework. BMC Bioinforma 2008, 9:212.

84. Talavera G, Castresana J: Improvement of phylogenies after removing divergent and ambiguously aligned blocks from protein sequence alignments. Syst Biol 2007, 56:564-577. 
85. Benjamini $Y$, Hochberg $Y$ : Controlling the false discovery rate - a practical and powerful approach to multiple testing. J Roy Stat Soc B Met 1995, 57:289-300

86. Hall TA: BioEdit: a user-friendly biological sequence alignment editor and analysis program for Windows 95/98/NT. Nucl Acids Symp Ser 1999, 41:95-98.

87. Yang ZH, Wong WSW, Nielsen R: Bayes empirical Bayes inference of amino acid sites under positive selection. Mol Biol Evol 2005, 22:1107-1118.

88. Letunic I, Doerks T, Bork P: SMART 6: recent updates and new developments. Nucleic Acids Res 2009, 37:D229-D232.

89. Bendtsen JD, Nielsen H, von Heijne G, Brunak S: Improved prediction of signal peptides: SignalP 3.0. J Mol Biol 2004, 340:783-795.

90. Eisenhaber B, Schneider G, Wildpaner M, Eisenhaber F: A sensitive predictor for potential GPI lipid modification sites in fungal protein sequences and its application to genome-wide studies for Aspergillus nidulans, Candida albicans, Neurospora crassa, Saccharomyces cerevisiae and Schizosaccharomyces pombe. J Mol Biol 2004, 337:243-253.

doi:10.1186/1471-2148-12-229

Cite this article as: Nygren et al: Analyses of expressed sequence tags in Neurospora reveal rapid evolution of genes associated with the early stages of sexual reproduction in fungi. BMC Evolutionary Biology 2012 $12: 229$

\section{Submit your next manuscript to BioMed Central and take full advantage of:}

- Convenient online submission

- Thorough peer review

- No space constraints or color figure charges

- Immediate publication on acceptance

- Inclusion in PubMed, CAS, Scopus and Google Scholar

- Research which is freely available for redistribution 